\title{
Isolated Langerhans Cell Histiocytosis of the Thyroid in an Adult Female: One-Year Followup
}

\author{
Ramon Vilallonga, ${ }^{1}$ Andrea Ciudin, ${ }^{2}$ José Manuel Fort, ${ }^{1}$ Juan Antonio Baena, ${ }^{1}$ \\ Oscar Gonzalez, ${ }^{1}$ Manuel Armengol, ${ }^{3}$ Jordi Mesa, ${ }^{2}$ and Mari Carmen Ruiz Marcellán ${ }^{4}$ \\ ${ }^{1}$ Endocrine, Bariatric and Metabolic Unit, General Surgery Department, University Hospital Vall d'Hebron, 08035 Barcelona, Spain \\ ${ }^{2}$ Endocrinology Department, University Hospital Vall d'Hebron, 08035 Barcelona, Spain \\ ${ }^{3}$ General Surgery Department, University Hospital Vall d'Hebron, Passeig de la Vall d'Hebron 119-129, 08035 Barcelona, Spain \\ ${ }^{4}$ Pathology Department, University Hospital Vall d'Hebron, 08035 Barcelona, Spain
}

Correspondence should be addressed to Ramon Vilallonga, vilallongapuy@hotmail.com

Received 16 October 2010; Revised 9 December 2010; Accepted 13 January 2011

Academic Editor: Leon Bach

Copyright ( $) 2011$ Ramon Vilallonga et al. This is an open access article distributed under the Creative Commons Attribution License, which permits unrestricted use, distribution, and reproduction in any medium, provided the original work is properly cited.

Thyroid gland involvement as the unique presentation of Langerhans cell histiocytosis is a rare phenomenon that can result in misdiagnosis. We report a case of Langerhans cell histiocytosis (LCH) presenting as a thyroid mass. It is a 52-year-old woman who presented an enlarged, diffusely firm, nontender, nonmobile, and not particularly nodular thyroid gland with mild compressive symptoms. Ultrasound and fine-needle aspiration showed a unique right node with benign signs. Patient was referred to our Ambulatory Surgery Department, where a hemithyroidectomy was performed. Histologic evaluation of the right thyroid gland revealed an involvement by LCH, confirmed by immunohistochemical analysis showing Langerhans cells that were positive for CD1a. LCH was a completely incidental occult finding apparent only after surgical resection and examination of the gland. Patient was evaluated, and no evidence of systemic affectation was found. LCH can rarely involve the thyroid gland in adults. Few cases have been reported in the literature. Most patients had evidence of LCH involving other anatomic sites.

\section{Introduction}

Langerhans cell histiocytosis (LCH) involving the thyroid is a very rare condition, which presents typically with involvement of bone, lung, skin, the hypothalamus/posterior pituitary gland, lymph nodes, and multiple sites. [1] Few cases have been reported of thyroid gland infiltration by LCH as isolated involvement. [2] We do present a case of isolated thyroid involvement by LCH.

\section{Case Report}

A 52-year-old woman who presented with an enlarging thyroid mass was referred to our Surgical Department for evaluation. Physical examination of the patient revealed an enlarged, diffusely firm, nontender, nonmobile, and not particularly nodular thyroid gland with mild compressive symptoms. This thyroid gland revealed no tenderness, and the overlying skin was not erythematous. Preoperative endocrine evaluation revealed normal levels for thyroxine (T4; $7.2 \mu \mathrm{g} / \mathrm{dL}$, normal range 4.9-13), tri-iodothyronine (T3; $109 \mathrm{ng} / \mathrm{dL}$, normal range 80-185), and thyroid-stimulating hormone (TSH; 3. $99 \mu \mathrm{U} / \mathrm{mL}$, normal range $0.6-5.5$ ).

Ultrasound showed diffusely, hypoechoic thyroid with dimensions of $36 \times 20 \times 16 \mathrm{~mm}$ on the right and $36 \times$ $16 \times 17 \mathrm{~mm}$ on the left. A unique nodule with dimensions was found in the right lobe. The ultrasound could not see any other lesions. A fine-needle aspiration confirmed the diagnosis of hyperplasic nodule. The patient then underwent a right hemithyroidectomy to remove this enlarging and compressing node in the Ambulatory Surgery Department.

\section{Pathological Findings}

The thyroid gland specimens are routinely processed, formalin-fixed, and paraffin-embedded; histologic sections 


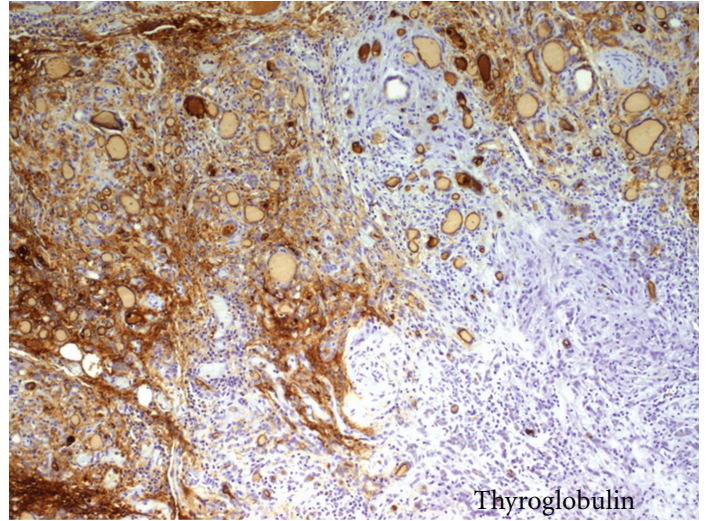

Figure 1: Focus of polymorph infiltrate and histiocytic negative for thyroglobulin. Normal positives thyroid cells peripherally. (Immunohistochemical Biotin-streptavidin Technique. 100x)

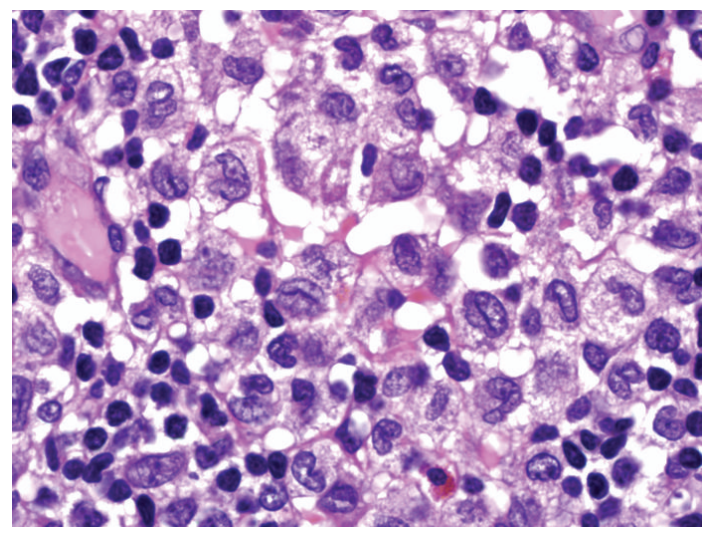

FIGURE 2: HE of the focus of histiocytes. Focus histiocytic infiltrate with coffee bean morphology, lymphoid infiltrate with eosinophils. (H.E. 200x)

are stained with hematoxylin and eosin (H\&E). Immunohistochemical stains are performed on representative formalinfixed paraffin sections at our institution using a biotinstreptavidin method with appropriate controls. The specimen was assessed for expression of CD1a, S-100 protein, leukocyte common antigen (LCA, CD45). Other studies included thyroglobulin.

The right thyroid gland removed was $14.5 \mathrm{~g}$ and measured $30 \times 25 \times 25 \mathrm{~mm}$. The node was occupying more than 3 of the 4 parts of the right lobe. The node measured $30 \times$ $20 \times 20 \mathrm{~mm}$ and appeared to be an adenoma. All thyroid enlargement was due to the hyperplasic node. At the isthmus zone, a central white area was observed to be measured $10 \times$ $6 \times 5 \mathrm{~mm}$.

Histological evaluation revealed LCH. On low magnification, there was no evidence of a distinct, well-circumscribed mass. Sheets of discohesive mononuclear cells separated large areas of normal appearing thyroid follicles. On closer examination, these cells contained a moderate to abundant amount of pale to eosinophilic cytoplasm with deeply clefted, slightly eccentric nuclei characteristic of LCs. In focal areas,

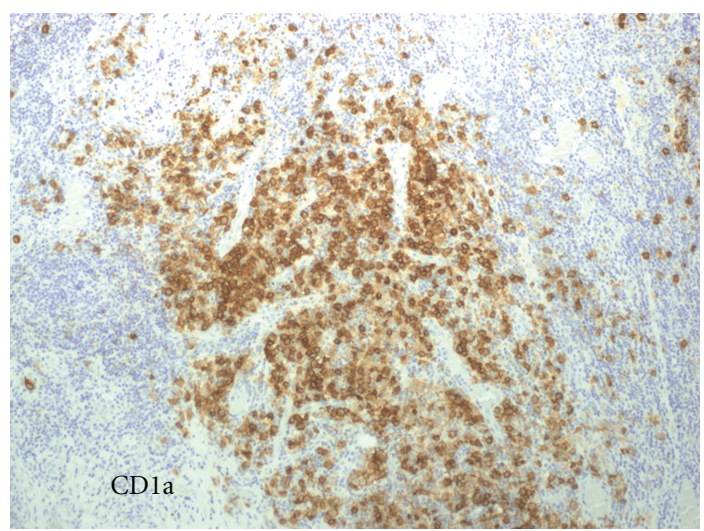

FIGURE 3: CD1a-positive histiocytes. (Immunohistochemical streptavidin-biotin Technique. 100x)

the LC infiltrate appeared to merge with the adjacent follicular epithelium, and individual tumour cells were seen within thyroid epithelium and in follicle lumina (Figure 1). The LCs were negative for epithelial membrane antigen, thyroglobulin (Figure 2). The LCs were strongly positive for CD1a with a diffuse cytoplasmic pattern of staining (Figure 3).

This LCH appeared to be an incidental almost occult finding in a thyroid that was resected for an enlarging, compressing thyroid adenoma. A retrospectively review of the preoperative ultrasound images with the radiologist could not detect the incidental finding of the LCH node.

Following surgery, a whole-body bone scan and skull $\mathrm{X}$-ray were done, followed by bone marrow aspiration and examination, all of which revealed no definitive evidence of any disease involvement. Urine analysis, a complete blood cells count, erythrocyte sedimentation rate, and serum biochemistry (electrolytes, alkaline phosphatase, and liver function) all yielded results within the normal ranges. At this stage, a definitive diagnosis of isolated $\mathrm{LCH}$ of the thyroid was made. After 1-year followup, no evidence of systemic disease has been proven.

\section{Discussion}

$\mathrm{LCH}$ is a rare disease with an incidence rate of 4.0-5.4 per 1 million individuals, and the most common endocrinological manifestation of classical LCH is associated with posterior pituitary involvement presenting as diabetes insipidus [3]. Some other manifestations such as hypothalamic/pituitary axis disturbance and anterior pituitary deficiency can be less frequently observed, resulting in secondary or tertiary hypothyroidism [4]. Also the condition typically presents with the involvement of bone, lung, skin, lymph nodes, and multiple sites [5]. However, LCH involving the thyroid gland is extremely rare, and there are very few reported cases, especially when it is a unique location [6]. Most of the cases present as a diffuse or nodular thyroid enlargement and as multisystemic disease, and only few cases were reported as isolated involvement of the thyroid by $\mathrm{LCH}[7,8]$. Because 
LCH involving the thyroid gland is rare, it is not really possible to comment on the frequency of such completely occult lesions from the available literature.

Thyroid involvement is more common in adults and has a relatively indolent course. Thyroid involvement of LCH can be indistinguishable from other thyroid disorders presenting with goiter. It is important to distinguish isolated thyroid LCH from multisystemic cases because single organ involvement is associated with an excellent survival of close to $100 \%$ [9]. For this reason a complete study in order to diagnose a systemic affection is important.

However, cases have been reported, where LCH has been initially misdiagnosed as poorly differentiated carcinoma of the thyroid [10].

Therefore, diagnosing these patients is quite challenging for a clinician [7-9]. Not only the physical signs but also the thyroid hormone status, antithyroid antibodies, sonographic and scintigraphic findings may be similar [11-13]. Physical examination usually reveals a multinodular or a diffusely enlarged thyroid as in our patients. They tend to present with a palpable nodule or in other cases as a diffusely enlarged goiter of one or two lobes [9]; this nonspecific presentation is easily confused with far more common benign goiters or thyroid neoplasms $[7,9]$.

Antithyroid antibodies, especially antithyroglobulin antibody, may be elevated. However, elevation of antimicrosomal antibodies, as detected in our second case, has not been documented before. This finding reminds us to keep primary thyroid LCH in mind, as well as thyroid carcinoma and autoimmune thyroiditis, in the differential diagnosis of thyroid disorders presenting with multinodular goiter [14].

Some cases have been reported, where LCH has been initially misdiagnosed as poorly differentiated carcinoma of the thyroid. According to the literature, primary LCH and carcinoma of the thyroid were synchronously reported in adults $[12,13]$. On review of previous biopsies and when clinical suspicion of LCH is high, histologic support for the diagnosis of LCH can usually be found.

For the diagnosis, ultrasonography and fine-needle aspiration are first-line modalities for the workup of thyromegaly [15], when large histiocytes with abundant cytoplasm interspersed in a background of lymphocytes and eosinophils are seen after FNA examination in the typical presentation of LCH [6]. According to this technique, thyroid fineneedle aspiration is useful in establishing the diagnosis, but Langerhans cells are occasionally misdiagnosed as atypical follicular epithelial cells and others. Also, as mentioned above, papillary carcinoma has been reported to coexist with LCH within the thyroid gland [9].

Surgical treatment is the suitable option. For localized LCH to the thyroid, resection of LCH by subtotal, near total, or total thyroidectomy is the treatment of choice $[7,9]$. No date has been able to show that it is necessary to perform the systemic chemotherapy; however, additional investigations such as thoracic CT, whole-body bone scintigraphy, and abdominal ultrasonography, as well as prolonged followup, are suggested [9].

\section{Conclusion}

In conclusion, we should consider that isolated LCH of the thyroid is quite rare during infancy and should be considered in the differential diagnosis. In adults, systemic LCH affection has to been studied. A local excision of the thyroid is the treatment of choice, and prolonged followup is recommended in these patients.

\section{Acknowledgement}

The Dr. Ramon Vilallonga Foundation has participated with the financial support to prepare the manuscript. (http://www .fundacioramonvilallonga.org/).

\section{References}

[1] D. D. Elliott, R. Sellin, J. F. Egger, and L. J. Medeiros, "Langerhans cell histiocytosis presenting as a thyroid gland mass," Annals of Diagnostic Pathology, vol. 9, no. 5, pp. 267274, 2005.

[2] K. Lollar, T. Y. Farrag, D. Cao, J. Niparko, and R. P. Tufano, "Langerhans cell histiocytosis of the thyroid gland," American Journal of Otolaryngology, vol. 29, no. 3, pp. 201-204, 2008.

[3] J. Donadieu, M. A. Rolon, C. Thomas et al., "Endocrine involvement in pediatric-onset Langerhans' cell histiocytosis: a population-based study," Journal of Pediatrics, vol. 144, no. 3, pp. 344-350, 2004.

[4] B. Rami, U. Schneider, K. Wandl-Vergesslich, H. Frisch, and E. Schober, "Primary hypothyroidism, central diabetes insipidus and growth hormone deficiency in multisystem langerhans cell histiocytosis: a case report," Acta Paediatrica, International Journal of Paediatrics, vol. 87, no. 1, pp. 112-114, 1998.

[5] D. M. Howarth, G. S. Gilchrist, B. P. Mullan, G. A. Wiseman, J. H. Edmonson, and P. J. Schomberg, "Langerhans cell histiocytosis diagnosis, natural history, management, and outcome," Cancer, vol. 85, no. 10, pp. 2278-2290, 1999.

[6] P. H. Lieberman, C. R. Jones, R. M. Steinman et al., "Langerhans cell (eosinophilic) granulomatosis: a clinicopathologic study encompassing 50 years," American Journal of Surgical Pathology, vol. 20, no. 5, pp. 519-552, 1996.

[7] R. J. Behrens, A. W. Levi, W. H. Westra, D. Dutta, and D. S. Cooper, "Langerhans cell histiocytosis of the thyroid: a report of two cases and review of the literature," Thyroid, vol. 11, no. 7, pp. 697-705, 2001.

[8] F. Braiteh and R. Kurzrock, "Case 1. Langerhans cell histiocytosis of the thyroid," Journal of Clinical Oncology, vol. 24, no. 3, pp. 522-523, 2006.

[9] C. S. Hung, Y. C. Yeh, J. C. Chen, S. M. Jung, I. J. Hung, and F. S. Lo, "Isolated Langerhans cell histiocytosis of the thyroid in a female infant," European Journal of Pediatrics, vol. 166, no. 11, pp. 1151-1153, 2007.

[10] W. S. Wang, J. H. Liu, T. J. Chiou, R. K. Hsieh, C. C. Yen, and P. M. Chen, "Langerhans' cell histiocytosis with thyroid involvement masquerading as thyroid carcinoma," Japanese Journal of Clinical Oncology, vol. 27, no. 3, pp. 180-184, 1997.

[11] M. Sahoo, A. K. Karak, D. Bhatnagar, and C. S. Bal, "Fineneedle aspiration cytology in a case of isolated involvement of thyroid with Langerhans cell histiocytosis," Diagnostic Cytopathology, vol. 19, no. 1, pp. 33-37, 1998. 
[12] K. Teja, H. Sabio, D. R. Langdon, and A. J. Johanson, "Involvement of the thyroid gland in histiocytosis X," Human Pathology, vol. 12, no. 12, pp. 1137-1139, 1981.

[13] N. Goldstein and L. J. Layfield, "Thyromegaly secondary to simultaneous papillary carcinoma and histiocytosis X. Report of a case and review of the literature," Acta Cytologica, vol. 35, no. 4, pp. 422-426, 1991.

[14] B. Yağc1, N. Kandemir, N. Yazıcı et al., "Thyroid involvement in Langerhans cell histiocytosis: a report of two cases and review of the literature," European Journal of Pediatrics, vol. 166, no. 9, pp. 901-904, 2007.

[15] T. Y. Farrag, F. R. Lin, C. W. Cummings et al., "Importance of routine evaluation of the thyroid gland prior to open partial laryngectomy," Archives of Otolaryngology-Head and Neck Surgery, vol. 132, no. 10, pp. 1047-1051, 2006. 


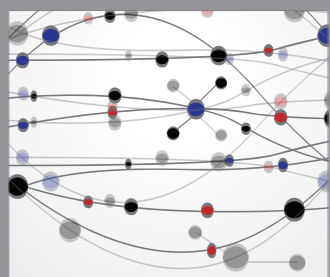

The Scientific World Journal
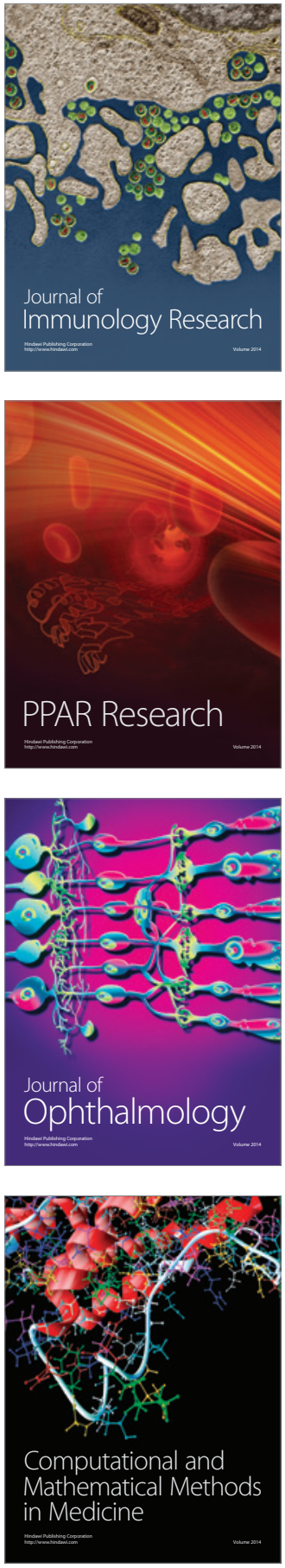

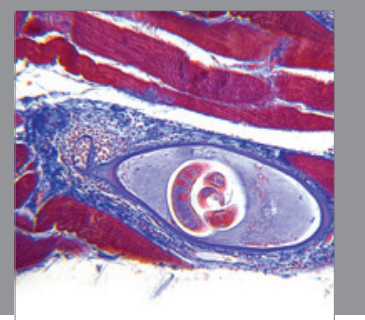

Gastroenterology

Research and Practice
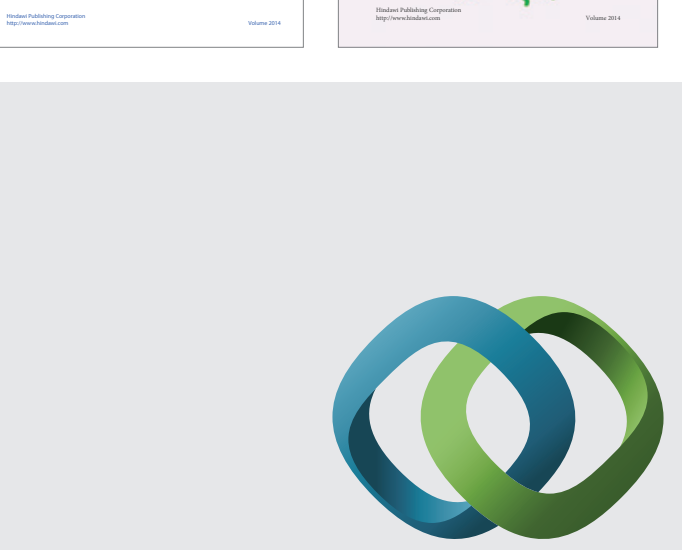

\section{Hindawi}

Submit your manuscripts at

http://www.hindawi.com
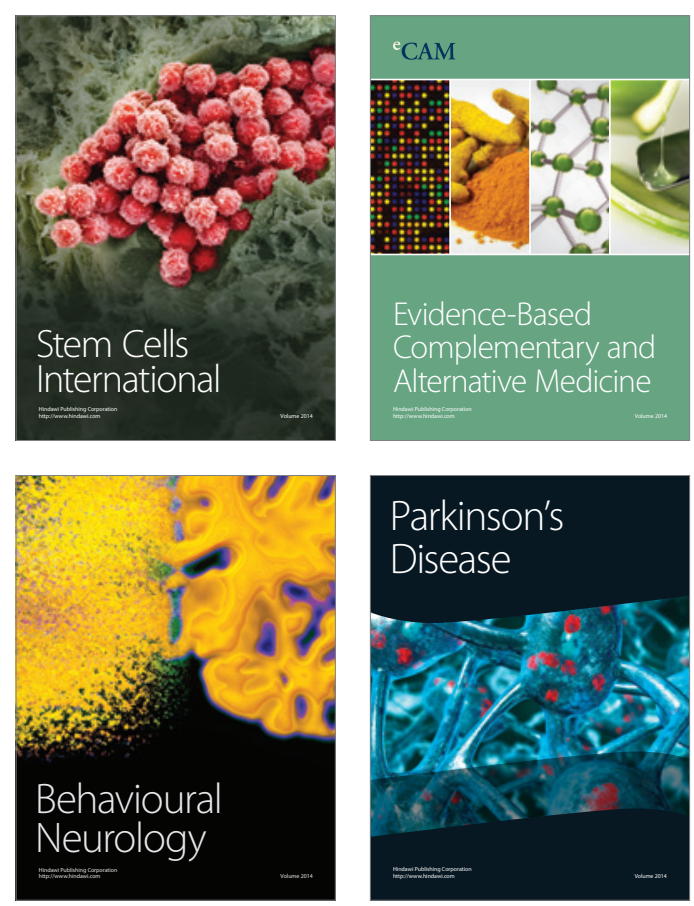

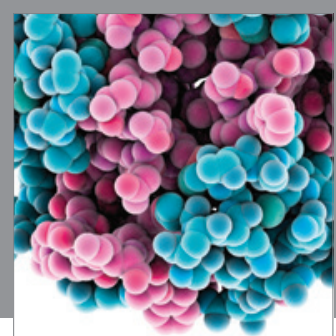

Journal of
Diabetes Research

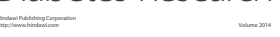

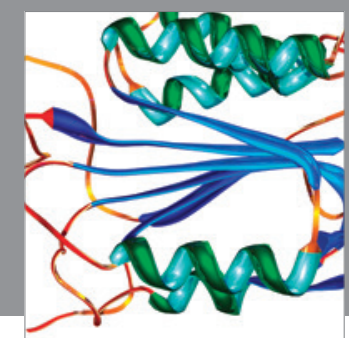

Disease Markers
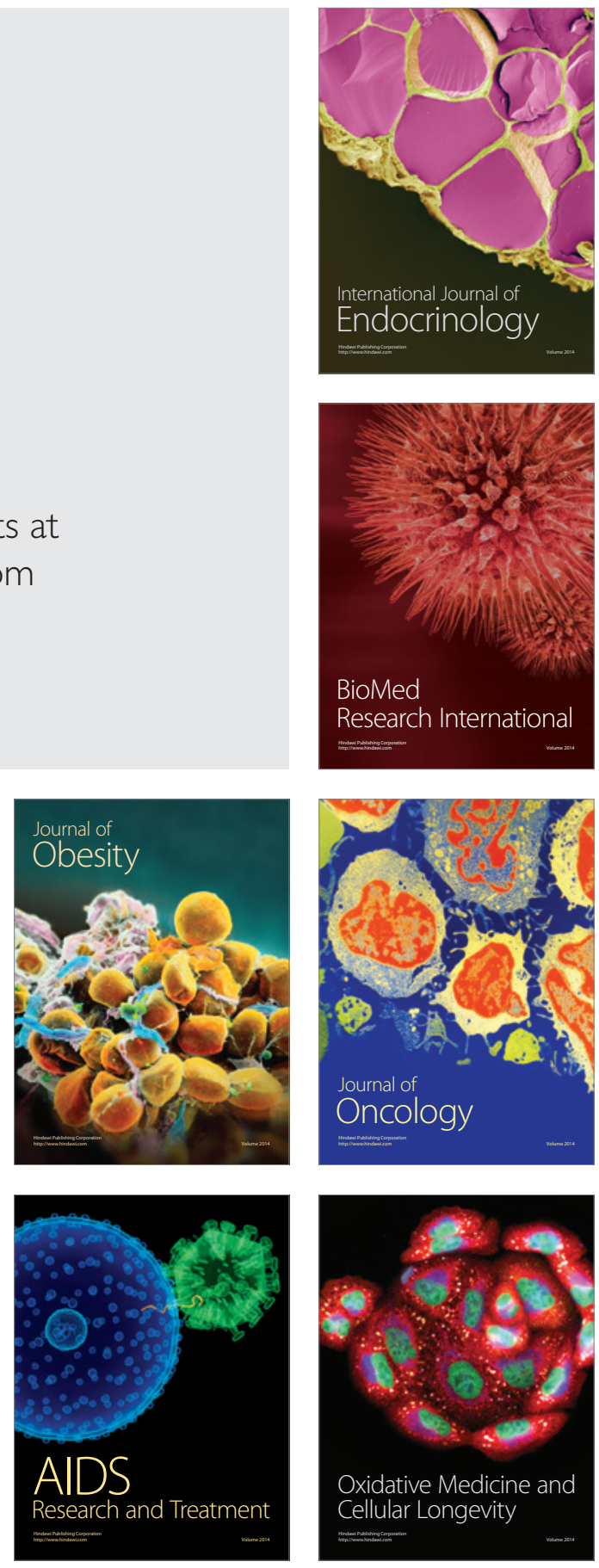